\title{
Habitat degradation from intermittent hypoxia: impacts on demersal fishes
}

\author{
Lisa A. Eby ${ }^{1,3, *}$, Larry B. Crowder ${ }^{1}$, Catherine M. McClellan $^{1}$, Charles H. Peterson ${ }^{2}$, \\ Monica J. Powers ${ }^{2}$
}

${ }^{1}$ Duke University Marine Laboratory, 135 Duke Marine Laboratory Road, Beaufort, North Carolina 28516, USA

${ }^{2}$ Institute of Marine Sciences, University of North Carolina at Chapel Hill, 3407 Arendell Street, Morehead City, North Carolina 28557, USA

${ }^{3}$ Present address: Wildlife Biology Program, College of Forestry and Conservation, The University of Montana, 32 Campus Drive, Missoula, Montana 59812, USA

\begin{abstract}
As eutrophication of estuaries and coastal oceans increases worldwide, the resulting expansion of hypoxic zones represents an increasingly frequent form of habitat degradation. Although impacts of prolonged hypoxia on benthic invertebrate species are well-documented, there is little understanding of how those effects subsequently influence the motile upper trophic levels in estuarine ecosystems. Quantitative nekton surveys in the Neuse River Estuary and field experiments in June and August 1999 using Atlantic croaker Micropogonias undulatus demonstrated that intermittent hypoxia decreased habitat quality for juvenile, demersal fish through 3 pathways: (1) hypoxia restricted the fishes in estuaries to shallow, oxygenated areas, where in the early part of the summer about $1 / 3$ fewer prey resources were available. (2) This contraction of suitable habitat crowded the fish into smaller areas and may have resulted in density-dependent reduction of growth rates. (3) Most importantly, mortality of sessile infauna in deeper areas exposed to intermittent hypoxia decreased prey densities about 8-fold between the June and August experiments. Through these mechanisms, intermittent hypoxia may result in ecological crunches or bottlenecks. Field data collected from May to October in 3 yr (1998 to 2000) with differing levels of hypoxia support the conclusion that intermittent hypoxia may decrease habitat quality and result in $\geq 50 \%$ declines in juvenile fish growth rate. Incorporation of these indirect effects of hypoxia on juvenile growth rates into a population model demonstrated the potential for significant $(\sim 4 \%)$ reductions in population growth rate. Thus, sublethal effects of hypoxia-driven habitat degradation may impact fisheries production not only through reduced size at age, but also through reduced abundance of demersal fish populations.
\end{abstract}

KEY WORDS: Habitat degradation · Hypoxia $\cdot$ Micropogonias undulatus $\cdot$ Leiostomus xanthurus Neuse River Estuary $\cdot$ Indirect effects $\cdot$ Population dynamics $\cdot$ Demersal fishes

\section{INTRODUCTION}

Understanding what regulates populations has been a central challenge in ecology for at least 50 yr (Krebs 1995). As humans continue to increase their domination over the earth's ecosystems (Botsford et al. 1997, Vitousek et al. 1997), scientific motivation has expanded from traditional questions of natural regulation to include studies of how human modifications to ecosystems alter population regulation. One incompletely explored process involves the mechanisms by which anthropogenic changes may impact populations by altering individual demographic rates. In aquatic systems, population-level effects of large-scale habitat degradation that result in direct mortality are often recognized, but sublethal effects of changes in growth rate, distribution or behavior have been more difficult to link directly to populations (Rose 2000). Explicitly 
demonstrating links between habitat characteristics or changes in environmental quality and fish population dynamics and production is critical to improving management, but it is rarely done (but see Landahl et al. 1997, Rose 2000), and is especially difficult in species that use multiple habitats throughout their life.

Saltwater spawning is one of the most common nektonic life histories that involve the use of estuaries. Many fishes spawn in coastal waters, and their larvae are subsequently transported into estuaries, where juveniles spend weeks to years before migrating offshore to the adult feeding and spawning grounds (Day et al. 1989). In many of these species, larval survival and recruitment into the estuary is considered the most critical stage influencing subsequent year-class strength (Houde 1994, Petrik et al. 1999). For example, 2 abundant species along the SE coast of the USA, Atlantic croaker Micropogonias undulatus and spot Leiostomus xanthurus, have a life history in which adults live and spawn offshore, larvae recruit into the estuary, and juveniles remain there for 6 to 15 mo (Lassuy 1983, Phillips et al. 1989). Similar to other species with this life history, there is a substantial interannual variation in the intensity of larval recruitment into the estuary (Houde 1994). Currin et al. (1984) and Kamermans et al. (1995) hypothesized that there is little to no resource limitation among juveniles of these common demersal species in SE USA estuaries, implying that the major determinant of a good year class for these species is typically larval survival.

Alternatively, anthropogenic estuarine habitat changes could have both direct and indirect effects on juvenile survival of demersal fishes. A common and growing source of habitat degradation in coastal environments worldwide, including estuaries along the eastern and southern borders of the USA, is the formation of severely hypoxic $\left(<2 \mathrm{mg} \mathrm{l}^{-1}\right)$ bottom waters (Diaz \& Rosenberg 1995, NRC 2001), primarily resulting from increased nutrient loading into coastal waters (Cooper \& Brush 1991, Paerl et al. 1998). In shallow, wind-driven systems, the formation of summertime hypoxia is an intermittent phenomenon associated with warm temperatures and resulting high rates of microbial activity and physical stratification of the water column (e.g. Lenihan \& Peterson 1998, Buzzelli et al. 2001). Although these events are intermittent, they can be extensive (covering 10s to $1000 \mathrm{~s}$ of $\mathrm{km}$ ) and last from days to weeks (Lenihan \& Peterson 1998, Paerl et al. 1998). As a result, mass mortality of sessile benthic invertebrates can occur and fishes and other mobile animals can experience periods of physiological stress or low growth from resulting resource limitation. During these times, that may constitute 'ecological crunches or bottlenecks' (Wiens 1977), competition for limited prey resources may become intense. Whether such events have population- or community-level effects is a function of the spatial extent, intensity, frequency and duration of the hypoxia and the abundance of benthic invertebrate prey relative to predator demand (Borsuk et al. 2002). If anthropogenic changes modify the characteristics of hypoxia sufficiently to reduce prey abundance on the bottom habitat to a level where prey becomes limiting to fish growth, then the degradation in water quality becomes linked indirectly to fish production and perhaps also to their population dynamics.

Although oxygen depletion is one factor that can directly cause fish kills in estuaries (Burkholder et al. 1992, 1999, Paerl et al. 1998), fishes typically swim out of hypoxic areas (Pihl et al. 1991, Breitburg 1992, Howell \& Simpson 1994). In the Neuse River Estuary, demersal fish are restricted to the shallow, oxygenated edges (depths of $<1.5 \mathrm{~m}$ ) during periods of hypoxia (Eby \& Crowder 2002). Although direct effects are minor, there is increasing evidence for indirect effects of these hypoxic events, including contraction of demersal fish habitats (e.g. Breitburg 1992, Lenihan et al. 2001, Eby \& Crowder 2002), increases in predatorprey overlap (Breitburg 1994, Breitburg et al. 1999), changes in benthic invertebrate assemblages (e.g. Diaz \& Rosenberg 1995), and shifts in diet composition of benthic fishes (Pihl et al. 1992, Pihl 1994).

Cascading effects of intermittent hypoxia from benthic habitat degradation and invertebrate losses to population responses of demersal fishes have not yet been demonstrated in the estuarine environment (Peterson et al. 2000). Some studies have described how these intermittent disturbances affect predator feeding rates in the short term (Pihl et al. 1992, Pihl 1994, Nestlerode \& Diaz 1998), but no study has extended over a sufficient time frame to link changes in growth and condition to production and population dynamics in an estuarine fish. Hypoxic zones may alter prey availability for juvenile benthic fishes through several pathways. (1) Intermittent hypoxia may stress the large benthic infauna so that they move to the sediment surface, increasing their short-term availability to predators (Pihl et al. 1992, Pihl 1994, Norkko \& Bonsdorff 1996). (2) During an hypoxic episode, fish distributions are restricted to shallow oxygenated areas (Eby \& Crowder 2002). If shallow areas have consistently lower invertebrate abundances, then prey availability is decreased. Similarly, if shallow areas have suboptimal temperature, then fishes' growth potential is decreased (Craig et al. 2001). (3) Hypoxia may crowd fishes at high enough densities to induce densitydependent decreases in growth from resource depletion or interference competition. (4) Exposure to extended periods of hypoxia can cause mortality of sessile, invertebrate prey resources, thus decreasing the value of the habitat for future use by fishes until 
recovery of the prey resources occurs (Thomson 1998, Sullivan \& Gaskill 1999, Baird et al. 2004).

We took a 3-tiered approach to determine impacts of intermittent hypoxia on benthic invertebrates and resulting responses of demersal fishes (Atlantic croaker Micropogonias undulatus and spot Leiostomus xanthurus) in the Neuse River Estuary of North Carolina, USA. (1) We conducted field experiments to evaluate potential effects of seasonal prey loss and fish density on juvenile growth rates in Atlantic croaker. (2) We examined whether the influence of intermittent hypoxic zones could be detected at an estuary-wide scale by quantifying changes over the summer in feeding, condition and growth of juvenile spot and Atlantic croaker among years that varied in both duration and extent of hypoxia. (3) We used an existing population matrix model (Diamond et al. 2000) to examine whether observed sublethal effects on juvenile Atlantic croaker growth were large enough to influence population growth rates. Matrix models have proven a valuable tool in assessing different population-level impacts of perturbations and management actions (e.g. Crouse et al. 1987, Crowder et al. 1994, Heppell et al. 1996), despite necessary simplifications and uncertainties (Caswell 1989).

\section{MATERIALS AND METHODS}

Study site. The Neuse River (North Carolina, USA) drains a $16000 \mathrm{~km}^{2}$ watershed that contains forests, animal and agricultural operations, several urban and suburban areas, and light industrial development. The estuary extends over $70 \mathrm{~km}$ and has an average width of $6.5 \mathrm{~km}$ (Buzzelli et al. 2001). Average depth of the Neuse River Estuary is $3.6 \mathrm{~m}$ and bottom-water salinity typically ranges from 0 psu at New Bern to 20 psu at the mouth of the estuary in the Pamlico Sound (Buzzelli et al. 2001, Eby \& Crowder 2002). This estuary is primarily a low-flow, wind-driven system with a variable salt wedge, which causes a wide range of hydrographic conditions from vertically homogeneous to strongly stratified (Robbins \& Bales 1995). Between May and September during stratified conditions, intermittent hypoxia and anoxia often occur below the mixed layer, lasting from a few hours to several weeks (Lenihan \& Peterson 1998, Paerl et al. 1998, Lenihan et al. 2001). Our study site was in the upper section of the estuary and spans approximately $88 \mathrm{~km}^{2}$ (Fig. 1).
Field experiment. To assess whether periodic hypoxia reduces prey densities and thereby limits growth of juvenile demersal fishes, we performed in situ cage experiments to examine croaker growth before (June 1999) and after (August 1999), a period of sustained hypoxia. These experiments were conducted at 2 fish densities and 2 depths (a shallower site unaffected by and a deeper site exposed to sustained low dissolved oxygen concentrations). Our strategy was to place the deeper site in an area that would be periodically hypoxic over the summer, but experience little hypoxia during the experimental periods. This allowed us to use growth rates from experimental croaker as a bioassay for indirect effects of hypoxia on fish growth resulting from modification of benthic prey resources. Thus, we also sampled benthic prey in the experimental study areas to indicate whether any observed treatment effects on fish growth could be explained by differences in prey density.

We collected juvenile Atlantic croaker Micropogonias undulatus in the Neuse River Estuary with a

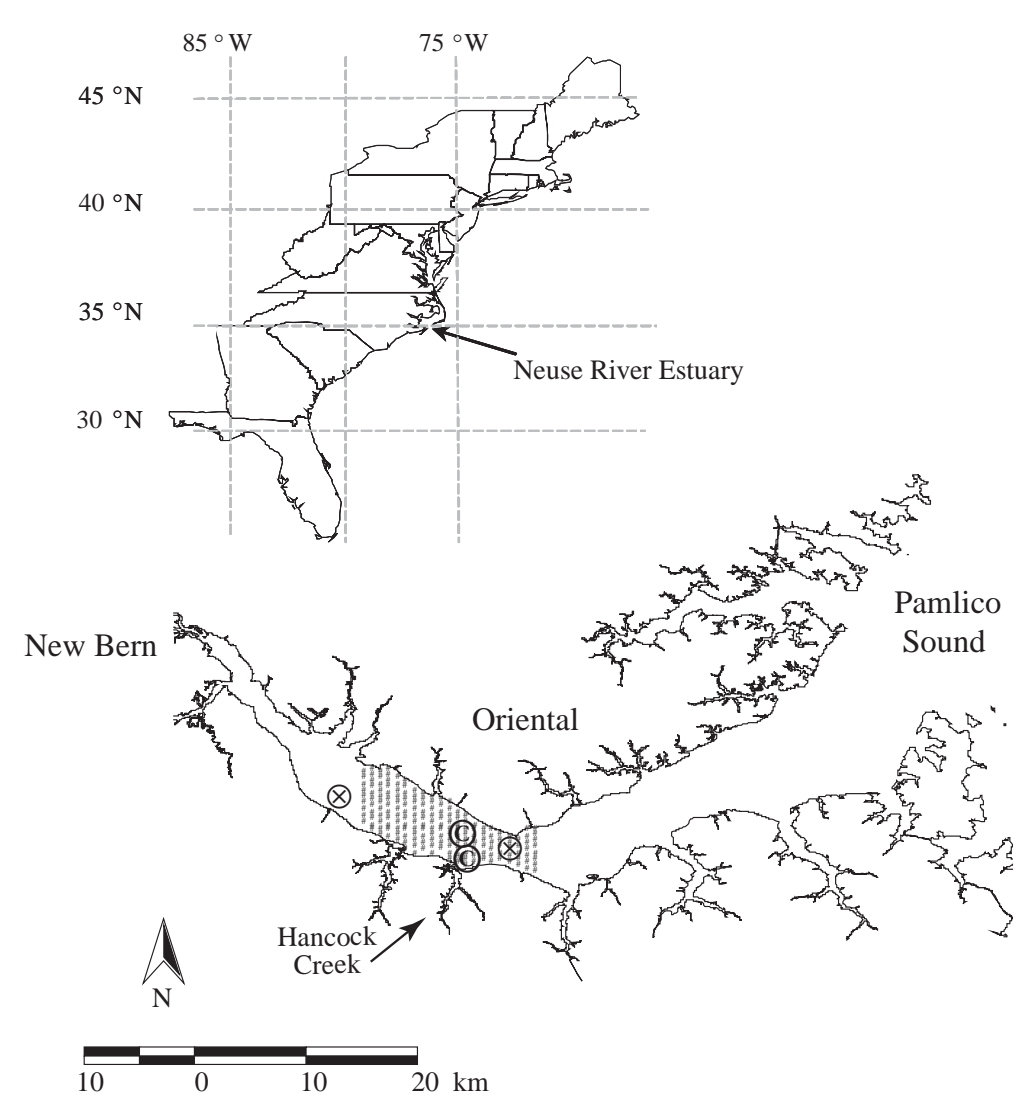

Fig. 1. Neuse River Estuary study area. Dots across river: survey stations that were randomly subsampled for demersal fishes from 1997 to 2000; $(\otimes)$ locations of US Geographical Survey (USGS) stations that continuously monitored water quality; Stn LT 11 is slightly upstream of survey area and LT 9 is within study area; (C) placement of cage experiment 
$3.05 \mathrm{~m}$ otter trawl using short $(<5 \mathrm{~min})$ tows. Fish were stored in aerated coolers and observed for 2 to $4 \mathrm{~h}$ to ensure that there was no injury or signs of stress from trawling. We then measured the total length (TL in $\mathrm{mm}$ ) and individually marked the croaker by fin clips, and deployed them into cages. Juvenile croaker were placed in $1.5 \mathrm{~m}^{2}$ cages constructed from $2.5 \mathrm{~cm}$ PVC pipe frames enclosed with $6.4 \mathrm{~mm}$ plastic mesh on the top and sides and $12.8 \mathrm{~mm}$ plastic mesh on the bottom. The larger mesh on the cage bottom allowed the croaker to feed on sediment-dwelling prey. The cages effectively excluded large fishes and crabs. Experimental cages were installed near Hancock Creek (Fig. 1). Although we performed this experiment in only one area of the estuary, data from a widespread coring survey in 1997 and 1998 had demonstrated that the benthic invertebrate community at this site, and its changes from early to late summer, were representative of the entire estuary (Thomson 1998, Sullivan \& Gaskill 1999, Baird et al. 2004).

We tested 4 treatments using a 2-way factorial design: depth (shallow versus deep) and fish density (high versus low) with 4 or 5 replicate cages per treatment. Based on previous monitoring in 1997 and 1998 (Selberg et al. 2001, Eby \& Crowder 2002), we expected the shallower site to remain well-oxygenated and the deeper site to be intermittently hypoxic for days to weeks during the summer. Low-density treatments consisted of 1 fish per cage $\left(0.67\right.$ fish $\left.\mathrm{m}^{-2}\right)$ and high-density treatments comprised 6 fish in June ( 4 fish $\mathrm{m}^{-2}$ ) and 4 fish in August (2.67 fish $\mathrm{m}^{-2}$ ). The number of croaker stocked in the high-density treatments was based on croaker densities estimated from the upper estimates of our summertime trawl catches (Eby 2001) adjusted for 25\% catch efficiency (Kjelson \& Johnson 1978). The highest croaker density estimates in the Neuse River Estuary were 10, 4.3, and 4.1 fish $\mathrm{m}^{-2}$ for 1998, 1999, and 2000, respectively.

Atlantic croaker (TL: mean $99 \mathrm{~mm}$; range 90 to $110 \mathrm{~mm}$ ) were stocked in 18 cages during the first week of June. Cages for each depth treatment were spaced 2 to $3 \mathrm{~m}$ apart along a depth contour. The boundaries of the shallower and deeper site were each marked with buoys, and GPS coordinates of the cages were taken. Cages were deployed for 20 to $23 \mathrm{~d}$ (mean 21.5 d). During each experiment, temperature (TEM), salinity (SAL), dissolved oxygen (DO), and water depth (DEP) were recorded once daily (between 08:00 and 10:00 h) at both experimental sites using a HydroLab DataSonde. At the end of each experiment (June and August), we retrieved the fish from the cages, measured their total length, and preserved the stomachs in $10 \%$ buffered formalin stained with Rose Bengal. Stomach samples were sieved through a $0.5 \mathrm{~mm}$ mesh and transferred into $70 \%$ ethanol. Stomach contents were examined under 10 to $100 \times$ magnification and frequency of occurrence and numbers of prey were recorded to family level.

We repeated the experiment in August by deploying the cages in the same general location, but we avoided placing them in the exact spot of the June experiment. The same experimental procedure was used with 2 exceptions: (1) Juvenile croaker were larger in August (TL: mean $128 \mathrm{~mm}$; range 115 to $135 \mathrm{~mm}$ ), so the highdensity treatment was reduced to 4 fish per cage to retain a similar fish biomass ( 65 g) in each highdensity cage. (2) The experimental duration was $17 \mathrm{~d}$ (range 16 to $18 \mathrm{~d}$ ), abbreviated because of the impending arrival of Hurricane Dennis in late August.

Individual growth rates were averaged to obtain a single growth datum for each high-density cage. Fish growth potential changed between June and August because of different water temperatures and fish sizes between the experimental periods, so we analyzed each experiment separately (June and August). We transformed the growth rate data using logarithms, tested for homoscedasticity using Cochran's $C$-test $(\alpha<$ 0.05 ) and analyzed growth rate data using a 2 -factor ANOVA. There were no trends in the residuals. In addition, we examined the proportion of fish that survived, as this can confound a growth response. We transformed the proportion of fish that survived using arcsine square-root, and checked for normality before analyzing the data using a 2-factor ANOVA.

We took benthic cores before and after the experiment to quantify macrofaunal density and community composition. Cores were $10 \mathrm{~cm}$-diameter aluminum tubes inserted to a depth of $25 \mathrm{~cm}$. We stored the core contents on ice and sieved them through $0.5 \mathrm{~mm}$ mesh within $24 \mathrm{~h}$. Retained material was preserved in $10 \%$ buffered formalin and stained with Rose Bengal. Benthic samples were transferred to $70 \%$ ethanol and all invertebrates were picked from the remaining sediment and debris. We examined samples under 6 to $50 \times$ magnification and identified invertebrates to family, except bivalves, which were identified to species. We transformed the density data using a square-root $(x+$ 1) transformation, tested for homoscedasticity with Cochran's $C$-test $(\alpha<0.05)$, and for each experimental period analyzed the data using Student's $t$-test (treatments: shallow and deep).

Field patterns. Field surveys of fish (Micropogonias undulatus and Leiostomus xanthurus) abundance were conducted monthly from May through October in 1998, 1999 and 2000. At each sampling, we randomly chose 30 to 40 (mean of 36) stations from a fixed grid of 85 stations placed over the study area (Fig. 1) and sampled these during daylight over a $2 \mathrm{~d}$ period. We measured water quality parameters (depth, temperature, salinity and dissolved oxygen) along a continuous depth profile 
before and after each trawl with a portable CTD probe (SeaBird SBE-25-03). We determined position with a Garmin Geopositioning System unit. Because CTD data are recorded at 8 readings $\mathrm{s}^{-1}$ during the depth profile, we averaged measurements from the lowest $0.25 \mathrm{~m}$ to represent bottom water conditions.

Fish were sampled with a $9 \mathrm{~m}$ mongoose trawl (48 $\mathrm{mm}$ mesh wings and body with a $13 \mathrm{~mm}$ mesh tailbag), pulled for $2 \mathrm{~min}$ at 2 to 3 knots by a $19 \mathrm{~m}$ research vessel. We recorded species abundance, and a random subsample of up to 100 individuals of each species per trawl was measured (TL). We standardized fish catches (number $100 \mathrm{~m}^{-1}$ towed) using trawl time and boat speed. From 1998 through 2000, subsamples of up to 20 croaker and 20 spot per trawl were frozen for later analyses of TL, standard length (SL in $\mathrm{mm}$ ), wet weight (W in $\mathrm{g}$ ) of each fish, and weight ( $\mathrm{g}$ ) of stomach and contents.

During the study period (1998 to 2000), the Neuse River Estuary experienced varying degrees of hypoxia. Contrasting fish data from different summers allowed us to assess whether feeding (stomach and content wet weight/fish wet weight), body condition and growth rate differences in juvenile croaker and spot varied with intensity of hypoxia. We compared feeding, condition, and growth indices from juvenile spot and croaker captured in the trawl survey with spot and croaker abundance, TEM, SAL and DO among the 3 summers.

Within and just upstream of the study area, the US Geological Survey (USGS) maintains 2 permanently moored continuous water-quality monitoring stations (Fig. 1; http://nc.water.usgs.gov/info/h2o.html). The top sensor is $2.7 \mathrm{~m}$ from the bottom and the bottom sensor is $0.7 \mathrm{~m}$ from the bottom. Measurements comprised $\mathrm{pH}, \mathrm{DO}$, specific conductance, SAL and TEM. We used the USGS data to determine the duration of bottom-water hypoxia, which was used to make contrasts in severity among years. (1) We calculated the proportion of days that bottom-water hypoxia occurred at the study site. We summed all days in June, July and August with average bottom dissolved oxygen concentrations $<2.0 \mathrm{mg} \mathrm{l}^{-1}$ at either USGS station, and divided the result by the total number of days with data. Data were reported for at least $87 \%$ of the days in the 3 mo summer period (1998: 83 of 92 d, 1999: 80 of 92 d, 2000: 90 of 92 d). (2) Because many benthic invertebrates can survive short exposure to hypoxia, we examined both the number of events with continuous hypoxia for at least $7 \mathrm{~d}$ and the maximum duration of each hypoxic episode. (3) We used our CTD data to estimate the spatial extent of bottom-water hypoxia for each sampling cruise. We calculated the spatial extent of hypoxia in the study area by entering the bottom DO measurements into a geographical information system, using latitude and longitude from the GPS records. We interpolated the DO data in ArcView Spatial Analyst using the inverse-distance weighting method (ESRI ArcView; www.esri.com/software/arcgis/arcview/index. $\mathrm{html}$ ). The number of pixels in the interpolated map that were $<2.0 \mathrm{mg} \mathrm{l}^{-1}$ was divided by the total number of pixels in the study area to determine the percent of the study area with hypoxic bottom waters for each sampling date. For each summer these numbers were averaged to compare among years. We calculated average TEM and SAL for each summer from the same CTD data set.

We computed an index of fish feeding (stomach wet weight/fish wet weight) and examined trends among the 3 yr. Because sizes of juveniles varied, we divided stomach weight by fish weight to normalize the data. These proportions were transformed using arcsine square-root to approximate a normal distribution (Zar 1984, p 239-241). To examine how the availability of benthic food may have changed across summers in years that varied in intensity of hypoxia, we calculated the difference between the means of this feeding index in June and August for each year. We computed change in condition over the summer by subtracting the mean condition index $\left(\mathrm{W} \mathrm{SL}^{-3}\right)$ in August from the June value. In August 2000, fewer than 40 individual fish of each species were measured to estimate body condition, so only 1998 and 1999 could be used for this comparison. In 1998 and 1999, each mean feeding and condition index included at least 225 fish of each species (mean 760, range 225 to 1531 fish). We estimated average summer growth rates for croaker and spot from length-frequency distributions. Because we measured a subset of the catch, we weighted the lengthfrequency distribution for each station by trawl catch at that station to create a composite distribution for all stations on a sampling date. We then compared modes of the aggregated length-frequency distributions between our June and August samples. As our trawl could not catch the smaller fish in May, and by September and October some of the larger fishes had migrated out of the estuary (Day et al. 1989), limiting the comparisons between June and August minimized these biases. Because we only have 1 measure per season for each species, we simply ranked the different variables and responses for comparisons.

Model simulations. To project the potential population effects of observed inputs of these indirect effects of varying habitat quality on individual growth rate, we employed a published stage-within-age population matrix model for Atlantic croaker developed by Diamond et al. (2000). The model framework is an age-based matrix model with 8 year-classes (Table 1). In addition, the first year of life is partitioned into 6 separate stages based on ontogenetic shifts in mor- 
Table 1. Micropogonias undulatus. Stage duration, total instantaneous mortality rates stage survival rates, and fertility for Atlantic croaker taken from Diamond et al. (2000) (see Diamond et al. 1999 for derivation of parameters). In the first year of life, stage duration and mortality rates are measured on a daily time step, while after Age 1, survival rates are applied at yearly intervals. For adult stages, annual survival $S_{t}=\mathrm{e}^{-Z_{t}}$, where $\mathrm{Z}_{t}$ is the total annual instantaneous mortality rate at Age $t$. Fertility probabilities equal the probability of surviving to the end of each year multiplied by fecundity at the end of each year. For the first-year life stages, survival $\mathrm{S}_{i}=\mathrm{e}^{-\mathrm{Z}_{i} \mathrm{D}_{i}}$, where $\mathrm{Z}_{i}$ is the total instantaneous daily mortality rate at Stage $i$ and $D_{i}$ is stage duration at Stage $i$ (Diamond et al. 2000)

\begin{tabular}{|lrccc|}
\hline Stage & $\begin{array}{c}\text { Stage } \\
\text { duration }\end{array}$ & $\begin{array}{c}\text { Total } \\
\text { mortality }\end{array}$ & Survival & Fertility \\
\hline Egg & $2.0 \mathrm{~d}$ & 0.4984 & 0.3691 & \\
Yolk-sac larvae & $4.0 \mathrm{~d}$ & 0.1438 & 0.4871 & \\
Ocean larvae & $39.8 \mathrm{~d}$ & 0.1100 & 0.0125 & \\
Estuarine larvae & $65.9 \mathrm{~d}$ & 0.0245 & 0.2033 & \\
Early juvenile & $157.2 \mathrm{~d}$ & 0.0210 & 0.0405 & \\
Late juvenile & $99.6 \mathrm{~d}$ & 0.0130 & 0.2745 & 0.22 \\
Age 1 & $1 \mathrm{yr}$ & 0.97 & 0.3791 & 66771 \\
Age 2 & $1 \mathrm{yr}$ & 0.97 & 0.3791 & 110318 \\
Age 3 & $1 \mathrm{yr}$ & 0.97 & 0.3791 & 155670 \\
Age 4 & $1 \mathrm{yr}$ & 0.97 & 0.3791 & 201631 \\
Age 5 & $1 \mathrm{yr}$ & 0.97 & 0.3791 & 246185 \\
Age 6 & $1 \mathrm{yr}$ & 0.97 & 0.3791 & 283144 \\
Age 7 & & & & 317786 \\
\hline
\end{tabular}

phology and size. Each stage has a specific duration and daily mortality rate that is used to calculate survival associated with that stage on a daily time step. These calculations are then combined to compute survival in the first year of life in the age matrix. We used the published model as our baseline scenario and then altered the matrix model to incorporate the observed differences in juvenile Atlantic croaker growth rates associated with hypoxia. To represent Neuse River Estuary oxygen dynamics, we randomly drew from a probability distribution of the temporal extent of summertime hypoxia determined by a process-based model of oxygen dynamics in the Neuse River Estuary (Borsuk et al. 2001: see last paragraph of this section). Every run began with the same starting population size of $1 \times 10^{11}$ fish partitioned into the stable age distribution of the published model of Diamond et al. (2000).

We altered juvenile growth rates in response to different intensities of summertime hypoxia to reflect differences that we observed for Atlantic croaker in the experiments and field surveys. In the model, the transition from the early juvenile (5th) to late juvenile (6th) stage is a function of size (65 mm SL). Therefore, changes in the growth rate of estuarine juveniles during June, July and August alter the stage duration of the early and late juvenile stages. In addi- tion, Diamond et al. (2000) assumed that Atlantic croaker migration out of the estuary occurred on October 1, at which point they are about $115 \mathrm{~mm}$ SL. We assumed size-dependent migration out of the estuary, as is seen with Atlantic croaker in the Gulf of Mexico (Yakupzack et al. 1977) and in our Neuse River Estuary Atlantic croaker length-frequency data (Eby 2001).

In the model, we assumed that varying durations of hypoxia altered juvenile fish growth rates to varying degrees and subsequently modified juvenile fish stage (early and late) duration. For moderate hypoxia (15 to $30 \%$ of the summertime days hypoxic), we assumed that the croaker follow the same growth rate $\left(\sim 0.45 \mathrm{~mm} \mathrm{~d}^{-1}\right)$ and stage duration schedule as in the original model (our Table 1; Diamond et al. 2000). These baseline model parameters were derived from multiple years and estuaries across Virginia and North Carolina (Diamond et al. 1999). For years of extensive hypoxia (>30\% of the summertime days hypoxic), the juvenile croaker growth rate was set at $0.3 \mathrm{~mm} \mathrm{~d}^{-1}$ starting June 1. This growth rate estimate is similar to that observed for juvenile croaker in 1999 and 2000 in the field survey. In this case, the early juvenile stage lasts $164.8 \mathrm{~d}$ before reaching $65 \mathrm{~mm}$ SL. After this point, this fish displays the late juvenile mortality rate for $159 \mathrm{~d}$ until reaching $115 \mathrm{~mm}$ SL. In years with less hypoxia $(<15 \%$ of the summertime days hypoxic), juvenile croaker growth rates were faster $\left(0.6 \mathrm{~mm} \mathrm{~d}^{-1}\right)$ and stage durations of these sizebased juvenile stages were shortened (150.8 d for early juvenile and $83.6 \mathrm{~d}$ for the late juvenile). Although the field survey data support the use of an even higher growth rate for croaker $\left(\sim 0.8 \mathrm{~mm} \mathrm{~d}^{-1}\right)$, the average fish in the cages did not achieve this high level, but did reach $0.6 \mathrm{~mm} \mathrm{~d}^{-1}$. Therefore, this lower, conservative rate was used.

The probability distribution of the temporal extent of summertime hypoxia was created through Monte Carlo simulations of a process-based model of oxygen dynamics that was developed for the Neuse River Estuary (Borsuk et al. 2001). The environmental state for every year was drawn from this fixed distribution, independent of previous states. We compared output from runs of the baseline model with no variation in oxygen dynamics (Diamond et al. 2000) with model output that reflects recent Neuse River Estuary oxygen dynamics (Borsuk et al. 2001) to examine whether changes in juvenile growth rates associated with hypoxia could have a population level impact. The response variable was the stochastic population growth rate (ln $\lambda$, Caswell 2001). For the stochastic model, we calculated estimates of population growth rates from 100 different simulations, each of $5000 \mathrm{yr}$ (Caswell 2001). 


\section{RESULTS}

\section{Field experiment}

June cage experiment

In June, cages at the shallower site were deployed at a depth of $0.6 \mathrm{~m}$ into well-oxygenated water $(7.8 \mathrm{mg}$ $\mathrm{l}^{-1}$ ) and cages at the deeper site were placed $1.6 \mathrm{~m}$ deep, with dissolved oxygen concentrations just above $2.0 \mathrm{mg} \mathrm{l}^{-1}$ (Fig. 2). Throughout the experiment, depth varied by $>1 \mathrm{~m}$ at each site, depending on the wind direction, with the shallower site ranging from 0.3 to $1.6 \mathrm{~m}$ and the deep site from 1.4 to $2.7 \mathrm{~m}$. Hypoxic conditions never occurred in daily monitoring at the shallower site and occurred on only the second day of the experiment at the deeper site (Fig. 2). The mean DO concentrations $( \pm \mathrm{SE})$ for the shallower and deeper sites were $6.6( \pm 0.3) \mathrm{mg} \mathrm{l}^{-1}$ and $5.7( \pm 0.4) \mathrm{mg} \mathrm{l}^{-1}$, respectively. TEM and SAL were similar at both sites throughout the experiment (averaging $25.0 \pm 0.2^{\circ} \mathrm{C}$ and $11.8 \pm$ $0.2 \mathrm{psu}$ ), except on $3 \mathrm{~d}$ when the shallower site was 1 to $2^{\circ} \mathrm{C}$ warmer (Fig. 2).

Atlantic croaker in the cages had high survival. All fish in low-density cages survived the experiment at both depths. Survival in high-density cages averaged (+SE) 79\% $( \pm 2)$ in the shallower and $63 \%( \pm 4)$ in the deeper site. There was no significant effect of depth (ANOVA, $p=0.1$ ), but fish in the high-density treatment had a $30 \%$ lower survival $(p<0.001)$, and no significant interaction was present $(\mathrm{p}=0.1)$.

Daily average growth rates ranged from 0.0 to $1.0 \mathrm{~mm} \mathrm{~d}^{-1}$ with the highest mean growth rates $\left(0.59 \mathrm{~mm} \mathrm{~d}^{-1}\right)$ in the deeper, low-density treatment (Fig. 3). Fish at the shallower depth grew $30 \%$ less (average $0.15 \mathrm{~mm} \mathrm{~d}^{-1}$ ) than fish at the deeper site (average $0.45 \mathrm{~mm} \mathrm{~d}^{-1}$, site effect; $\mathrm{p}=0.044$ ) and fish in high-density treatments grew $68 \%$ less than fish caged alone ( 0.45 vs. $0.14 \mathrm{~mm} \mathrm{~d}^{-1}$, density effect $\mathrm{p}=0.034$ ). There was no significant interaction $(p=0.40)$, as illustrated by the parallel lines in Fig. 3.

We examined stomach contents to determine whether the croaker were feeding on typical prey items rather than items that might represent cage artifacts. Diet composition of croaker in cages was similar to that of similar-sized croaker collected from the Neuse River Estuary approximately $20 \mathrm{~km}$ downstream of our site in June 1998 (Thomson 1998, Sullivan \& Gaskill 1999). The only unusual prey item was the presence of nudibranch larvae in the stomachs of 2 of the caged fish (Table 2). Although this was probably a cage effect, there was no difference between sites in the low occurrence of this diet item (1 fish from each site).

June growth rates of juvenile croaker corresponded to differences in invertebrate density between the depths (Table 3). Benthic invertebrate densities were significantly $(\mathrm{p}<0.0001)$ higher at the deeper than at the shallower site. For example, clam Macoma
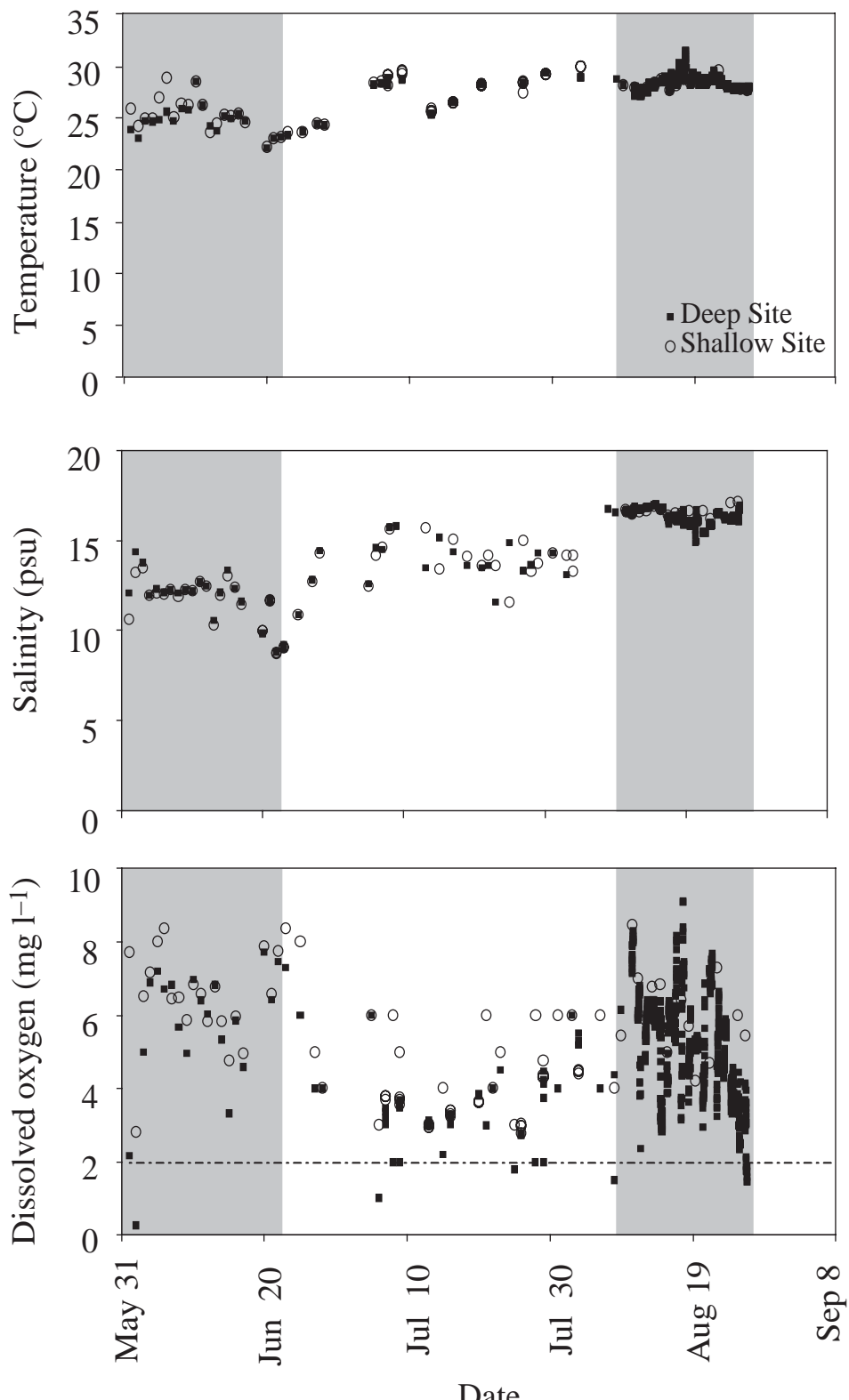

Fig. 2. Daytime temperature, salinity, and dissolved oxygen concentration at deeper and shallower cage sites; shaded areas indicate experimental periods. Sites were sampled daily during experiments, less frequently between experiments 


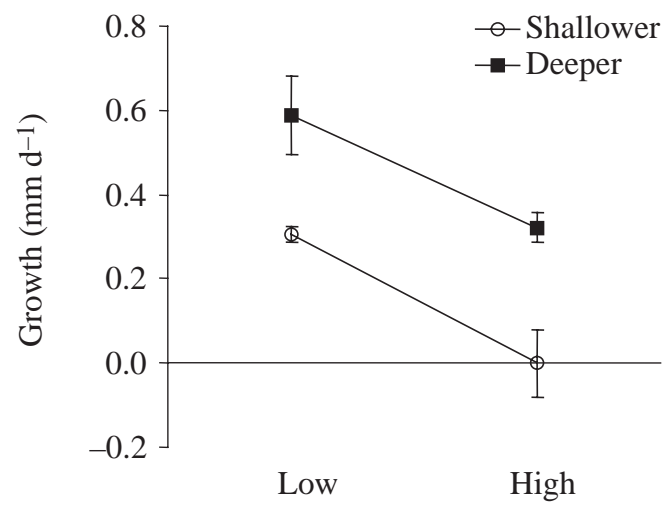

Fish density

Fig. 3. Micropogonias undulatus. Mean +1 SE growth rates (total length, $\mathrm{mm} \mathrm{d}^{-1}$ ) for both site (shallower and deeper) and density (low and high) treatments of June experiment

mitchelli and M. baltica density was 7 times higher at the deeper than at the shallower site $(p<0.0001)$ and polychaete density was 3 times higher $(p<0.0001)$. These 2 taxa made up $80 \%$ of the total invertebrate densities in the cores (Table 3) and, given their relatively large size, comprised an even higher fraction of the biomass.

Table 2. Micropogonias undulatus. Average frequency of occurrence $(\%)$ of diet items for field-collected croaker samples from 4 stations near South River (Fig. 1 and Thomson 1998) in June and September, and for caged croaker during June and August experiments. Overlap in diet items was high between field and caged croaker

\begin{tabular}{|lcccc|}
\hline \multirow{2}{*}{ Diet item } & \multicolumn{2}{c}{ Field } & \multicolumn{2}{c|}{ Cage } \\
& June & September & June & August \\
& & & & \\
Fish scales & 25.1 & 33.5 & 95.5 & 88.9 \\
Polychaete & 30 & 76.9 & 90.9 & 94.4 \\
Crab & 1.3 & 6.3 & 72.7 & 44.4 \\
Shell & 62.1 & 51.8 & 63.6 & 66.7 \\
Bivalve tissue & 75.3 & 91.6 & 40.9 & 22.2 \\
Amphipod & 0 & 8.4 & 40.9 & 0 \\
Copepod & 0 & 25.7 & 22.7 & 5.6 \\
Shrimp & 0 & 19.7 & 22.7 & 5.6 \\
Gastropod & 0 & 1.3 & 18.2 & 11.1 \\
Plant & 12 & 71.2 & 13.6 & 27.8 \\
Fish bone & 12.9 & 21 & 13.6 & 16.7 \\
Nematode & 1.3 & 0 & 9.1 & 11.1 \\
Insect & 6.3 & 1.3 & 9.1 & 0 \\
Chironomid & 1.3 & 2.6 & 9.1 & 0 \\
Unidentified & 1.5 & 0 & 4.5 & 5.6 \\
Isopod & 2.9 & 1.3 & 4.5 & 0 \\
Ostracod & 1.5 & 5 & 4.5 & 0 \\
Mysid & 0 & 0 & 4.5 & 0 \\
Hydroids & 0 & 0 & 0 & 85 \\
Nudibranch larvae & 0 & 0 & 9.5 & 0 \\
& & & & \\
\hline
\end{tabular}

August cage experiment

During the interval between the 2 experiments, the deeper portions of the estuary were periodically hypoxic (including 2 periods of $\geq 7$ continuous days, Fig. 4), while bottom waters at the shallower site remained oxygenated. During the August experiment, water depth at the shallower site ranged from 0.5 to $1.2 \mathrm{~m}$, while that at the deeper site ranged from 1.1 to $2.5 \mathrm{~m}$. Salinity at the 2 sites was similar (average $+\mathrm{SE}$ : $16.4 \pm 0.02 \mathrm{psu}$ ), within $0.2 \mathrm{psu}$ each day (Fig. 2). As in the first experiment, temperatures at the 2 sites were similar (mean $\pm \mathrm{SE}: 28.5 \pm 0.03^{\circ} \mathrm{C}$ ), except on $3 \mathrm{~d}$ when the shallower site was $0.5^{\circ} \mathrm{C}$ warmer. At the shallower site, DO concentrations remained above $2.0 \mathrm{mg} \mathrm{l}^{-1}$, while at the deeper site hypoxia occurred on $\geq 3 \mathrm{~d}$ (Fig. 2). In August the average DO concentration was $6.1( \pm 0.3 \mathrm{SE})$ and $5.2( \pm 0.4 \mathrm{SE})$ at the shallower and deeper sites, respectively.

Survival was not affected by depth $(p=0.34)$ or density ( $p=0.98)$ and there was no interaction between these variables $(p=0.26)$. Most $(60 \pm 10.9 \% \mathrm{SE})$ of the croaker survived in low-density treatments at both depths. Mean survival in the high-density treatment was $87.5 \%( \pm 3.6)$ at the shallower site, but only $37.5 \%$ $( \pm 8.1)$ at the deeper site, which prevented data from the deeper site being used to estimate growth. We performed 1-way ANOVAs to separately test effects of site (shallower vs deeper for low fish density only) and fish density (low vs high density for the shallower site) on growth rates. There was no significant effect of depth on fish growth in the low-density cages $(p=0.76)$, but at the shallower site growth was about 2 times higher in the low- than in high-density cages ( $p=0.02$; Fig. 5).

Table 3. Total polychaete, Macoma spp., and invertebrate density by depth treatment for the 2 experimental periods (June and August 1999). Invertebrate density is ind. per core $($ core diameter $=10 \mathrm{~cm}$, depth of insertion $=25 \mathrm{~cm})$. SE: standard error of the mean for that treatment; $\mathrm{N}$ : sample size

\begin{tabular}{|c|c|c|c|c|}
\hline \multirow[t]{2}{*}{ Taxon } & \multicolumn{2}{|c|}{ - June -} & \multirow{2}{*}{\multicolumn{2}{|c|}{- August- }} \\
\hline & Shallower & Deeper & & \\
\hline \multicolumn{5}{|c|}{ Total polychaetes } \\
\hline Mean & 6.5 & 21.5 & 4.3 & 4.2 \\
\hline SE & 0.2 & 0.5 & 0.1 & 0.1 \\
\hline $\mathrm{N}$ & 27.0 & 25.0 & 27.0 & 26.0 \\
\hline \multicolumn{5}{|c|}{ Macoma spp. } \\
\hline Mean & 3.2 & 23.8 & 2.8 & 1.7 \\
\hline SE & 0.1 & 0.4 & 0.1 & 0.1 \\
\hline $\mathrm{N}$ & 27.0 & 25.0 & 27.0 & 26.0 \\
\hline \multicolumn{5}{|c|}{ Total invertebrates } \\
\hline Mean & 15.7 & 52.6 & 8.7 & 6.6 \\
\hline $\mathrm{SE}$ & 0.3 & 0.4 & 0.2 & 0.1 \\
\hline $\mathrm{N}$ & 27.0 & 25.0 & 27.0 & 26.0 \\
\hline
\end{tabular}




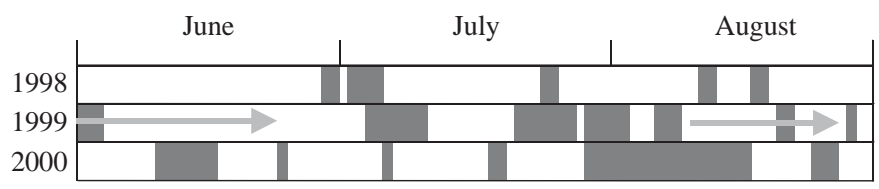

Fig. 4. Timeline indicating frequency and timing of hypoxia (grey bars) at USGS Stns LT 9 and LT 11 in upper Neuse River Estuary for each year. Arrows indicate timing of experiments in 1999

Stomach contents from caged croaker in August were similar to those in the June experiments and those of fish captured in the field downstream of our study in September 1998 (Thomson 1998). The only major difference was the widespread presence of hydroids (a cage artifact) in caged fish diets, with $85 \%$ frequency of occurrence (Table 2).

Similarities in growth rates between the depth treatments corresponded to food densities, as indicated by benthic invertebrates in the core samples (Table 3). In August, the density of benthic invertebrates did not differ between the deeper and shallower sites $(\mathrm{p}=$ 0.24). Macoma spp. and polychaetes made up about $86 \%$ of the total invertebrate density from these cores taken at the end of the experiment. These groups did not differ between the shallower and deeper sites (Macoma spp. $\mathrm{p}=0.30$, polychaetes $\mathrm{p}=0.59$ ). Polychaete density comprised $56 \%$ of the total invertebrate density in the cores (Table 3).

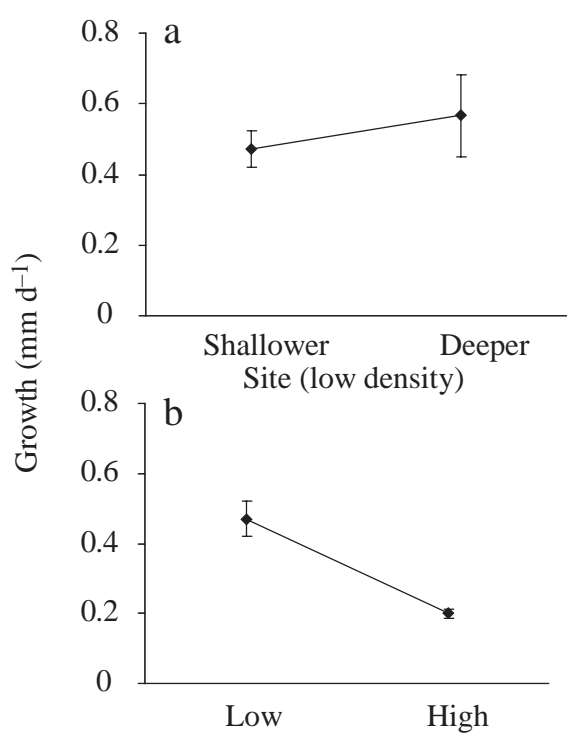

Fish density at shallower site

Fig. 5. Micropogonias undulatus. Growth data (total length, $\mathrm{mm} \mathrm{d}^{-1}$ ) for August experiments; there was low survival in the high-density, deeper cages. (a) Growth comparisons between deeper and shallower sites in low-density cages; (b) Growth rates in low- and high-density cages at the shallower site
Field survey

We analyzed 3 response variables (seasonal changes in feeding, condition and growth) to test whether they were related to summertime (June through August for 1998, 1999 and 2000) TEM, SAL, fish relative abundance, or hypoxia extent and duration in the upper Neuse River Estuary. Average summer temperatures (surface and bottom measures from USGS stations) were similar among the years. Average salinity (surface and bottom measures from USGS stations) in the summer of 1998 was less than half of that in 1999 or 2000 (Table 4). The spatial and temporal extent of hypoxia in the summer of 1998 was less than in either 1999 or 2000 (Table 4, Fig. 4). Trawl catches were variable in space and time, ranging from 0 to 10 Atlantic croaker $\mathrm{m}^{-2}$. Examination of relative abundance demonstrates that in 1998 Atlantic croaker was most abundant, in 1999 spot was the dominant species, and that the 2 species were approximately equal in abundance in 2000 . The blue

Table 4. Temperature, salinity, percent of days with hypoxic bottom waters, and duration of bottom-water hypoxia from US Geological Survey continuous monitoring stations located in mid-Neuse River Estuary (LT9 and LT11, Fig. 1) from June through August in 1998 to 2000. Average percent for study site with hypoxic bottom waters is from dissolved oxygen data from our water-quality and trawl surveys (see 'Materials and Methods'); croaker Micropogonias undulatus and spot Leiostomus xanthurus density estimates for the different years are from our trawl survey

\begin{tabular}{|c|c|c|c|}
\hline Year & 1998 & 1999 & 2000 \\
\hline \multicolumn{4}{|l|}{ Temperature $\left({ }^{\circ} \mathrm{C}\right)$} \\
\hline Mean & 27.8 & 27.3 & 26.6 \\
\hline Range & $23.8-30.5$ & $23.0-30.8$ & $21.8-29.2$ \\
\hline \multicolumn{4}{|l|}{ Salinity (psu) } \\
\hline Mean & 4.8 & 13.5 & 11.5 \\
\hline Range & $2.9-8.2$ & $11.1-19.5$ & $3.9-21.3$ \\
\hline Hypoxic days (\%) & 14 & 35 & 36 \\
\hline $\begin{array}{l}\text { No. of events }(\geq 7 \mathrm{~d}) \text { of } \\
\text { sustained bottom- } \\
\text { water hypoxia }\end{array}$ & 1 & 2 & 2 \\
\hline $\begin{array}{l}\text { Max. duration of bottom- } \\
\text { water hypoxia (d) }\end{array}$ & - 7 & 14 & 18 \\
\hline $\begin{array}{l}\text { Mean extent of hypoxia } \\
\text { in study area (\%) }\end{array}$ & 10 & 22 & 13 \\
\hline \multicolumn{4}{|c|}{ Atlantic croaker density (ind. $\mathrm{m}^{-2}$ ) } \\
\hline Mean & 0.34 & 0.26 & 0.10 \\
\hline Max. & 10.05 & 4.34 & 4.07 \\
\hline \multicolumn{4}{|l|}{ Spot density (ind. $\mathrm{m}^{-2}$ ) } \\
\hline Mean & 0.14 & 0.69 & 0.02 \\
\hline Max. & 1.67 & 7.14 & 0.78 \\
\hline \multicolumn{4}{|l|}{ Blue crab density (ind. $\mathrm{m}^{-2}$ ) } \\
\hline Mean & 0.02 & 0.08 & 0.12 \\
\hline Max. & 0.84 & 0.99 & 5.58 \\
\hline
\end{tabular}



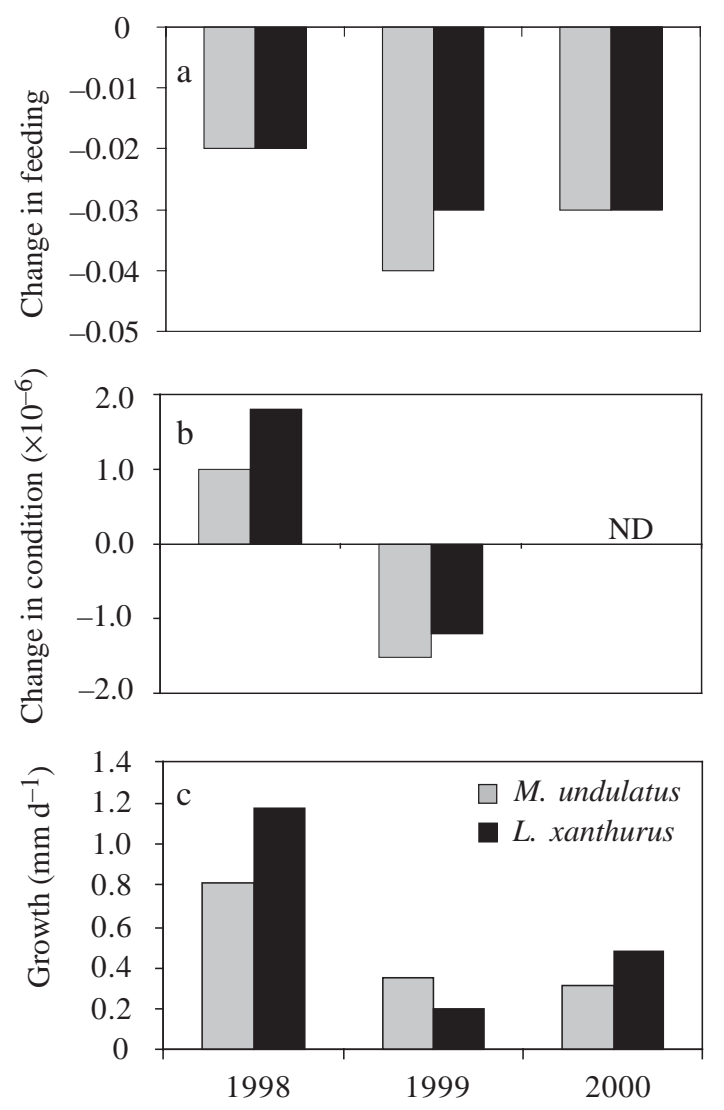

Fig. 6. Micropogonias undulatus and Leiostomus xanthurus. Comparison of feeding, condition and growth in Neuse River Estuary fish populations between years with varying hypoxic conditions; there were twice as many hypoxic days in 1999 and 2000 as in 1998 (Table 4). (a) Change in feeding indices (stomach weight/fish weight) for June to August; (b) change in condition indices ( $\mathrm{W} \mathrm{SL}^{-3}$ ) from June to August of juvenile $L$. xanthurus and $M$. undulatus; (c) growth rates $\left(\mathrm{mm} \mathrm{d}^{-1}\right)$ for June through August calculated from changes in modes of length-frequency distributions of fishes captured in trawls. nd: no data

crab Callinectes sapidus, another major predator on Macoma spp. exhibited its highest catches in 1999 and its lowest in 2000. Overall, total catch per unit effort (CPUE) for the 3 species combined was highest in 1999 and lowest in 2000 (Table 4).

Although there were seasonal decreases in the feeding indices between May and August for every year, there was a smaller decrease in 1998 than in either 1999 or 2000 (Fig. 6a). Croaker and spot condition (W $\mathrm{SL}^{-3}$ ) increased during the summer of 1998, whereas condition decreased during the summer of 1999 (Fig. 6b). Croaker and spot growth rates were twice as high in 1998 as in 1999 and 2000 (Fig. 6c). Limited data for indices of fish feeding, condition and growth (i.e. no replicates and only 3 data points) prevented statistical analysis. However, the year with the smallest decrease in feeding, highest condition, and fastest growth over the summer was the year with the least hypoxia (Table 4).

\section{Modeling results}

The model output reflecting Neuse River Estuary oxygen dynamics on juvenile growth rates resulted in a significantly lower population growth rate than the baseline (Diamond et al. 2000) scenario. The entire distribution of estimated $\ln \lambda$ (ln population growth rates) from each of the 100 iterations for the Neuse River Estuary scenario was lower than the baseline scenario $\ln \lambda$ (Fig. 7). This corresponds to about a $4 \%$ decrease in the estimated population growth rate $(\lambda)$ of croaker populations in the Neuse River Estuary versus the baseline scenario.

\section{DISCUSSION}

Extensive intermittent hypoxia can alter prey availability and ultimately result in decreased growth rates in juvenile demersal fishes during their estuarine stage. In addition, these changes in individual growth rates have the potential to reduce population growth rate. Indirect effects of hypoxia can be substantial, because these juvenile demersal fishes feed primarily on sessile infauna, which cannot escape hypoxic stress (Hodson et al. 1981, Peterson et al. 2000, Borsuk et al. 2002). Although the availability of these prey resources will vary with the intensity, duration and spatial extent of hypoxia, our results indicate that the current levels of hypoxia could be limiting to growth and production.

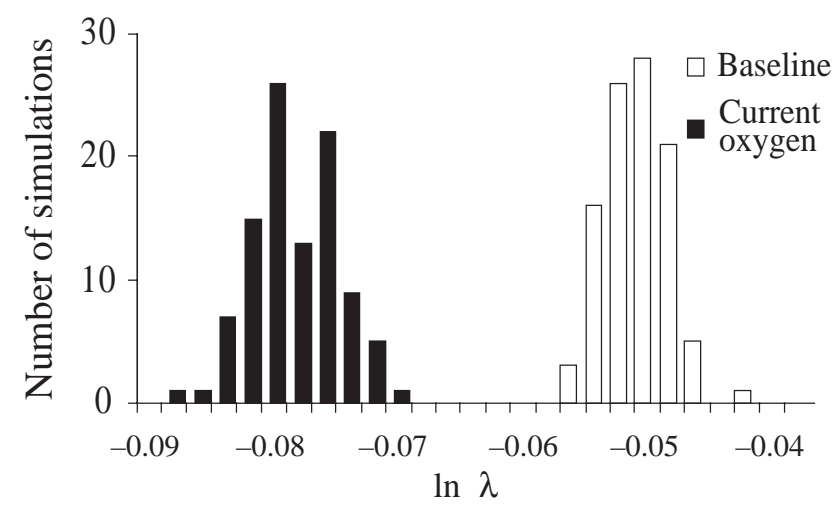

Fig. 7. Distributions of estimates of croaker Micropogonias undulatus population growth rates $(\ln \lambda)$ for each of 100 iterations of matrix model. Black and white bars indicate the Neuse River Estuary oxygen conditions and baseline scenarios, respectively 
Benthic sampling and cage experiments demonstrated a strong effect of hypoxia, altering prey availability for fishes through degradation of the habitat by killing invertebrate prey in deeper waters and potentially crowding fishes into shallow waters (Eby \& Crowder 2002). In our June experiments, the higher growth rates of croaker at the deeper site were probably mediated by the fact that the deeper site had invertebrate densities over twice those of the shallower site, given that temperature and salinity were similar between sites. Thus, habitat constriction in early summer caused by hypoxia in deeper waters forces juvenile demersal fishes into shallow areas with fewer prey resources, with the effect of reducing their growth rates.

Exposure of the deeper areas to extended periods of hypoxia in July and early August 1999 resulted in an 8-fold decline in invertebrate densities between June and August. Coring data from the entire Neuse River Estuary has similarly revealed large seasonal declines in invertebrates, particularly Macoma spp., over a large portion of the estuary, with declines increasing with growing intensity of hypoxia (Thomson 1998, Sullivan \& Gaskill 1999). Although benthic cores demonstrated reductions in Macoma spp. between June and September in both 1997 and 1998, the dramatic loss of clams in the deeper areas of the Neuse River Estuary was not as great in 1998 (Thomson 1998, Sullivan \& Gaskill 1999, Baird et al. 2004). In these 2 years the loss of benthos correlated with the spatial distribution of hypoxia and cannot be explained by differences in predation pressure (Baird et al. 2004). Although we did not sample benthic invertebrates in 1999 and 2000, these years were similar to 1997 in the spatial and temporal extent of hypoxia, suggesting a similar response of the benthic fauna.

Our study suggests that intermittent hypoxia can, and in the Neuse River Estuary did, decrease prey abundance and growth rates of estuarine demersal fishes through 3 potential mechanisms. (1) experiments in both June and August demonstrated the potential for density-dependent reductions in growth, mediated through enhanced reductions in prey abundance where predators are more concentrated. Although density-dependent growth rates were apparent in the cage experiments, there was no evidence of density-dependence in the field data. Even though our cages were calibrated to the higher field measures, these fish densities may have been a transient occurrence. (2) Another mechanism for this effect is the contraction of oxygenated habitat available to fishes during hypoxic episodes. Hypoxia in deep water restricts fishes to oxygenated shallows (Eby \& Crowder 2002), where early in the summer season feeding is likely to be less profitable because of lower prey densities, thereby decreasing fish growth rates. (3) Probably the most important effect is the loss of prey resources over the summer across most of the estuary (Thomson 1998, Sullivan \& Gaskill 1999). The deeper experimental site that experienced intermittent hypoxia demonstrated a large decline in invertebrate prey density. In addition, experimental croaker in August had a low occurrence of high-caloric prey, such as clam tissue and a higher occurrence of low caloric prey such as hydroids and plant matter, compared with the diets of those caged in June. This same trend of an increase in the frequency and abundance of low-calorie prey later in the season was observed in field-captured Atlantic croaker in the Neuse River Estuary (Sullivan \& Gaskill 1999).

Although exposure to hypoxia can reduce growth rates in fishes (e.g. Bedja et al. 1987), it is unlikely that this was the direct cause of observed differences in individual growth rates between the treatment sites. Caged croaker at deeper sites were exposed to occasional episodic hypoxia during both June and August 1999, but growth rates were highest in the deep site during June, implying that the indirect effects of hypoxia resulting from modification of prey resource abundance may overwhelm any direct effects of this short-term exposure to low dissolved oxygen on juvenile croaker growth.

We attribute differences in growth rates from the field survey to the differences in extent of hypoxia rather than salinity (1998 had the highest growth and lowest salinity). However, if salinity played a major role, we might expect the response of croaker and spot to vary, as these species have different salinity preferences (Lassuy 1983, Phillips et al. 1989) and are therefore likely to have different growth responses to salinity changes.

Our results support Breitburg's $(1992,1997)$ expectations that episodic hypoxic disturbances alter ecological interactions, both through increasing the potential for intra- and interspecific competition and by increasing predator/prey ratios after extensive hypoxic periods. These disturbances typically cause little to no direct fish mortality, and because fishes are motile, they can both leave the hypoxic area and recolonize quickly. Sessile invertebrates, however, are killed during sustained hypoxic disturbances, and must rely on passive transport of their motile life stage (usually larval) to reinvade the disturbed area (Powers et al. 2001). Consequently, predator/prey ratios (of benthic-feeding fish and crabs/ invertebrates) increase following such disturbances, and as available habitat is restricted, both antagonistic interactions and resource competition may become more intense. In addition to modifying prey availability in the disturbed area, prey depletion associated with motile predator accumulation in oxygenated refuges can transmit impacts of hypoxia indirectly to remote, undisturbed refuge habitats (Lenihan et al. 2001). If 
resources are limiting after the cessation of the disturbance, these constraints may persist as a legacy of the disturbance (as suggested by prey data in Lenihan et al. 2001). Similar to other physical disturbances, hypoxia affects lower trophic levels (zooplankton and/or benthic invertebrates) directly and induces cascades of effects propagating upwards through the food web (e.g. acidification: Frost et al. 1999).

Our conservative estimates of the effects of observed reductions in juvenile growth rate lead to a projected decrease in population growth rate. A change in population growth rate of this magnitude translates into substantial differences in population sizes. For example, after $25 \mathrm{yr}$, the population of croaker in the Neuse River Estuary scenario, reflecting current conditions of impaired water quality, would be only half the level predicted for the baseline scenario. A limitation of this model is that we have no information to parameterize potential effects associated with these disturbances that could impact demographic rates of other life stages that may covary with the effects that we modeled.

As we alter the estuarine habitat through nutrient loading and hypoxia, juvenile growth and survival may play a larger role in affecting both production and population regulation for demersal species. Achieving the goal of quantifying the effects of environmental quality on fish populations has been challenging because of the large amount of interannual variability in abundance. Using population data to extract these relationships will, at a minimum, require several decades of data - if it is possible given the multiple stresses on the systems and high recruitment variability associated with many coastal species. To effectively determine the extent of these effects on fish populations we need to develop a fundamental understanding of the mechanisms that link water quality to fish mortality, recruitment and growth. By isolating and quantifying the sublethal chronic effects on vital rates, the present study has identified some impacts on fish populations and demonstrated how declines in dissolved oxygen and subsequent degradation of bottom habitat reduces the suitability of estuarine habitats for demersal fishes and their associated fisheries.

Acknowledgements. We thank A. Read and S. Powers for insightful comments on this manuscript. We acknowledge everyone who worked in the field and the crew of RV 'Susan Hudson'. This work was funded by grants from the Environmental Protection Agency (Grant \#R26100-01-0), Water Resources Research Institute (Project \#50264, Project \#50220, and Project \#50263), NOAA North Carolina Sea Grant (Project R/MRD-37), and the J. F. Allen Award from the American Fisheries Society (L.A.E.). Although research described in this article has been funded in part by the United States Environmental Protection Agency through Grant \#R26100-01-0 to L.B.C. and A. Read, it has not been subjected to the Agency's required peer review, and policy review and therefore does not necessarily reflect the views of the Agency and thus no official endorsement should be inferred.

\section{LITERATURE CITED}

Baird D, Christian RR, Peterson CH, Johnson GA (2004) Consequences of hypoxia on estuarine ecosystem function: energy diversion from consumers to microbes. Ecol Appl 14:805-822

Bejda AJ, Studholme AL, Olla BL (1987) Behavioral responses of red hake, Urophycis chuss, to decreasing concentrations of dissolved oxygen. Environ Biol Fish 19:261-268

Borsuk ME, Stow CA, Luettich RA, Paerl HW, Pinckney JL (2001) Modelling oxygen dynamics in an intermittently stratified estuary: estimation of process rates using field data. Estuar Coast Shelf Sci 52:33-49

Borsuk ME, Powers SP, Peterson CH (2002) A survival model of the effects of bottom-water hypoxia on the population density of an estuarine clam (Macoma balthica). Can J Fish Aquat Sci 59:1266-1274

Botsford LW, Castilla JC, Peterson CH (1997) The management of fisheries and marine ecosystems. Science 277: 509-515

Breitburg DL (1992) Episodic hypoxia in Chesapeake Bay: interacting effects of recruitment, behavior, and physical disturbance. Ecol Monogr 62:525-546

Breitburg DL (1994) Behavioral response of fish larvae to low dissolved oxygen concentrations in a stratified water column. Mar Biol 120:615-625

Breitburg DL (1997) Varying effects of low dissolved oxygen on trophic interactions in an estuarine food web. Ecol Monogr 67:489-507

Breitburg DL, Rose KA, Cowan JH Jr (1999) Linking water quality to fish recruitment: predation mortality of fish larvae in an oxygen-stratified water column. Mar Ecol Prog Ser 178:39-54

Burkholder JM, Noga EJ, Hobbs CW, Glasgow HB, Smith SA (1992) New 'phantom' dinoflagellate is the causative agent of major estuarine fish kills. Nature 358:407-410

Burkholder JM, Mallin MA, Glasglow HB (1999) Fish kills, bottom-water hypoxia, and the Pfiesteria complex in the Neuse River and Estuary. Mar Ecol Prog Ser 179:301-310

Buzzelli CP, Powers SP, Luettich RA Jr, McNinch JE, Paerl HW, Peterson CH, Pinckney JL (2001) Estimating the spatial extent of bottom water hypoxia and benthic fishery habitat degradation in the Neuse River Estuary, North Carolina. Mar Ecol Prog Ser 230:103-112

Caswell H (1989) Matrix population models: construction, analysis and interpretation. Sinauer, Sunderland, MA

Caswell H (2000) Matrix population models: construction, analysis and interpretation, 2nd edn. Sinauer, Sunderland, MA

Cooper SR, Brush GS (1991) Long-term history of Chesapeake Bay anoxia. Science 254:992-996

Craig JK, Gray CD, McDaniel CM, Henwood TL, Hanifen JG (2001). Ecological effects of hypoxia on fish, sea turtles, and marine mammals in the northwestern Gulf of Mexico. In: Rabalais NN, Turner RE (eds) Coastal hypoxia: consequences for living resources and ecosystems. Coastal and estuarine studies, Vol 58. American Geophysical Union, Washington, DC, p 269-291

Crouse DT, Crowder LB, Caswell H (1987) A stage-based population model for loggerhead sea turtles and implications for conservation. Ecology 68:1412-1423

Crowder LB, Crouse DT, Heppell SS, Martin TH (1994) Pre- 
dicting the impact of turtle excluder devices on loggerhead sea turtle populations. Ecol Appl 4:437-445

Currin BM, Reed JP, Miller JM (1984) Growth, production, food consumption, and mortality of juvenile spot and croaker: a comparison of tidal and nontidal nursery areas. Estuaries 7:451-459

Day JE Jr, Hall CAS, Kemp WM, Yanez-Arancibia A (eds) (1989) Estuarine ecology. John Wiley \& Sons, New York, p 479-511

Diamond SL, Crowder LB, Cowell LG (1999) Catch and bycatch: the qualitative effects of fisheries on population vital rates of Atlantic croaker. Trans Am Fish Soc 128: 1085-1105

Diamond SL, Cowell LG, Crowder LB (2000) Population effects of shrimp trawl bycatch on Atlantic croaker. Can J Fish Aquat Sci 57:2010-2021

Diaz RJ, Rosenberg R (1995) Marine benthic hypoxia: a review of its ecological effects and the behavioral responses of benthic macrofauna. Oceanogr Mar Biol Annu Rev 33:245-303

Eby LA (2001) Response of a fish community to frequent and infrequent disturbances in an estuarine ecosystem. PhD dissertation, Duke University, Durham, NC

Eby LA, Crowder LB (2002) Hypoxia-based habitat compression in the Neuse River Estuary: context-dependent shifts in behavioral avoidance thresholds. Can J Fish Aquat Sci 59:952-965

Frost TM, Montz PK, Kratz TK, Badillo T and 8 others (1999) Multiple stresses from a single agent: diverse responses to the experimental acidification of Little Rock Lake, Wisconsin. Limnol Oceanogr 44:784-794

Heppell SS, Crowder LB, Crouse DT (1996) Models to evaluate headstarting as a management tool for long-lived turtles. Ecol Appl 6:556-565

Hodson RG, Hackman JO, Bennett CR (1981) Food habits of young spots in nursery areas of the Cape Fear River estuary, North Carolina. Trans Am Fish Soc 110:495-501

Houde ED (1994) Differences between marine and freshwater fish larvae: implications for recruitment. ICES J Mar Sci 51:91-111

Howell P, Simpson D (1994) Abundance of marine resources in relation to dissolved oxygen in Long Island Sound. Estuaries 17:394-402

Kamermans P, Guindon KY, Miller JM (1995) Importance of food availability for growth of juvenile southern flounder (Paralichthys lethostigma) in the Pamlico River estuary, North Carolina, USA. Neth J Sea Res 34:101-109

Kjelson MA, Johnson GN (1978) Catch efficiencies of a 6.1-m otter trawl for estuarine fish populations. Trans Am Fish Soc 107:246-254

Krebs CJ (1995) Two paradigms of population regulation. Wildl Res 22:1-10

Landahl JT, Johnson LL, Stein JE, Collier TK, Varanasi U (1997) Approaches for determining effects of pollution on fish populations of Puget Sound. Trans Am Fish Soc 126:519-535

Lassuy DR (1983) Species profiles: life histories and environmental requirements - Atlantic croaker. US Fish Wildl Serv Biol Serv Program FWS-OBS 82/11.3

Lenihan HS, Peterson CH (1998) How habitat degradation through fishery disturbance enhances impacts of hypoxia on oyster reefs. Ecol Appl 8:128-140

Lenihan HS, Peterson $\mathrm{CH}$, Byers JE, Grabowski JH, Thayer GH, Colby DR (2001) Cascading of habitat degradation: oyster reefs invaded by refugee fishes escaping stress. Ecol Appl 11:764-782

NRC (National Research Council) (2001) Clean coastal waters: understanding and reducing the effects of nutrient pollution. National Academy Press, Washington, DC

Nestlerode JA, Diaz RJ (1998) Effects of periodic environmen- tal hypoxia on predation of a tethered polychaete, Glycera americana: implications for trophic dynamics. Mar Ecol Prog Ser 172:185-195

Norkko A, Bonsdorff E (1996) Altered benthic prey-availability due to episodic oxygen deficiency caused by drifting algal mats. PSZN I: Mar Ecol 17:355-372

Paerl HW, Pinckney JL, Fear JM, Peierls BL (1998) Ecosystem responses to internal and watershed organic matter loading: consequences for hypoxia in the eutrophying Neuse River estuary, North Carolina, USA. Mar Ecol Prog Ser 166:17-25

Peterson $\mathrm{CH}$, Summerson HC, Thomson E, Lenihan HS, Grabowski J, Manning L, Micheli F, Johnson G (2000) Synthesis of linkages between benthic and fish communities as a key to protecting essential fish habitat. Bull Mar Sci 66:759-774

Petrik R, Levin PS, Stunz GW, Malone J (1999) Recruitment of Atlantic croaker, Micropogonias undulatas: do postsettlement processes disrupt or reinforce initial patterns of settlement? Fish Bull (Wash, DC) 4:954-961

Phillips JM, Huish MT, Kerby JH, Moran DP (1989) Species profiles: life histories and environmental requirements of coastal fishes and invertebrates-spot. US Fish Wildl Serv Biol Rep 82111.98

Pihl L (1994) Changes in diet of demersal fish due to eutrophication-induced hypoxia in the Kattegat, Sweden. Can J Fish Aquat Sci 51:321-336

Pihl L, Baden SP, Diaz RJ (1991) Effects of periodic hypoxia on distribution of demersal fish and crustaceans. Mar Biol 108:349-360

Pihl L, Baden SP, Diaz RJ, Schaffner LC (1992) Hypoxiainduced structural changes in the diet of bottom-feeding fish and Crustacea. Mar Biol 112:349-361

Powers SP, Harper DE Jr, Rabalais NN (2001) Effects of hypoxia/anoxia on the supply and settlement of invertebrate larvae. In: Rabalais NN, Turner GE (eds) Coastal hypoxia: consequences for living Resources and ecosystems. Coastal and estuarine studies, Vol 58. American Geophysical Union, Washington, DC, 185-210

Robbins J, Bales J (1995) Simulation model of hydrodynamics and solute transport in the Neuse River estuary, NC. USGS Open File Report No. 94-511. US Geological Survey, Raleigh, NC

Rose KA (2000) Why are quantitative relationships between environmental quality and fish populations so elusive? Ecol Appl 10:367-385

Selberg CD, Eby LA, Crowder LB (2001) Hypoxia in the Neuse River estuary: responses of blue crabs and crabbers. N Am J Fish Manag 21:358-366

Sullivan ET, Gaskill D (1999) Effects of anoxia on the value of bottom habitat for fisheries production in the Neuse River Estuary. Final Report for Fisheries Resource Grant 98 EP04, Department of Marine Fisheries, Morehead City, NC

Thomson EE (1998) Impacts of summer hypoxia on benthic fauna and implications for fisheries productivity in the Neuse River estuary, North Carolina. MS thesis, Institute of Marine Sciences, University of North Carolina, Chapel Hill

Vitousek PM, Mooney HA, Lubchencho J, Melillo JM (1997) Human domination of earth's ecosystems. Science 277: 494-499

Wiens JA (1977) On competition and variable environments. Am Sci 65:590-597

Yakupzack PM, Herke WH, Perry WG (1977) Emigration of juvenile Atlantic croaker, Micropogonias undulatus, from a semi-impounded marsh in southwestern Louisiana. Trans Am Fish Soc 106:538-544

Zar JH (1984) Biostatistical analyses, 2nd edn. Prentice Hall, Englewood Cliffs, NJ

Submitted: February 9, 2004; Accepted: September 21, 2004

Proofs received from author(s): April 5, 2005 